\title{
PAULO FREIRE E O TERRITÓRIO EDUCATIVO ALÉM MUROS DA ESCOLA: TRÊS CHAVES DE ACESSO A MÚLTIPLAS DIMENSÕES DE APRENDIZAGEM
}

\author{
Joanne Cristina Pedro ${ }^{1}$ \\ Nilda Stecanela ${ }^{2}$ \\ Sandro de Castro Pitano ${ }^{3}$
}

\section{RESUMO}

O estudo reflete sobre o cotidiano de uma comunidade de periferia da serra gaúcha e adota, como centralidade, a escola municipal do local e o território do entorno, explorando possibilidades de aprendizagem ao promover maior aproximação entre ambos. O desafio consiste em tematizar múltiplas dimensões de aprendizagem potencializadas por chaves de acesso categorizadas por meio das trilhas no território educativo (TE), nomeadas a partir de três metáforas: as chaves da rua; as chaves de si; as chaves do mundo. O TE como articulador de relações contribui para ampliação do aprendizado escolar, podendo funcionar como um disparador de aprendizagens que dialogam com saberes escolares e comunitários. A pesquisa-ação, envolvendo 15 jovens

\footnotetext{
${ }^{1}$ Mestre em Educação. Doutoranda do Programa de Pós-Graduação em Educação na linha de pesquisa História e Filosofia da Educação, com bolsa FAPERGS e vinculada ao Observatório de Educação da Universidade de Caxias do Sul. Possui especialização em Organização e Gestão de Políticas Sociais pela FMU (Faculdades Metropolitanas Unidas) e graduação em Psicologia pela Universidade Presbiteriana Mackenzie. ORCID: http://orcid.org/0000-0002-9290-0545. E-mail: jcpedro@ucs.br

2 Doutora em Educação. Desenvolveu estudos de Pós-Doutorado em Educação, como bolsista CAPES, no Institute of Education/University of London (2015-2016). Pró-Reitora Acadêmica, docente do corpo permanente do Programa de Pós-Graduação em Educação da Universidade de Caxias do Sul e Co-editora da Revista Conjectura: Filosofia e Educação. Coordena o Observatório de Educação da mesma instituição. É bolsista CNPq de Produtividade em Pesquisa.. ORCID: https://orcid.org/0000-0001-9946-0848. E-mail: nildastecanela@terra.com.br

${ }^{3}$ Doutor em Educação, Estágio de pós-doutorado - PNPD/CAPES (2013-2014) e pósdoutorado sênior/CNPq (2016-2017) pelo Programa de Pós-Graduação em Educação (ME/DO) da Universidade do Vale do Rio dos Sinos (UNISINOS). Professor do Programa de Pós-Graduação em Educação (ME/DO) da Universidade de Caxias do Sul (UCS) e bolsista CNPq de produtividade em pesquisa. ORCID: https://orcid.org/0000-0002-97941303. E-mail: scpitano@gmail.com
} 
estudantes, amparou-se em registros etnográficos; narrativas de grupos focais; definição das trilhas educativas; construção do mapa das aprendizagens 'além-muros' e registros fotográficos. A sustentação teórica considerou, principalmente, a obra de Paulo Freire, bem como Brandão e Streck, Moraes e Galiazzi, dentre outros. O detalhamento da metáfora das três chaves configura o principal achado da pesquisa: a relevância do território educativo para a aprendizagem, em suas dimensões espacial, identitária e política.

Palavras-chave: Paulo Freire. Território Educativo. Educação não Escolar. Cidadania.

\section{PAULO FREIRE AND THE EDUCATIONAL TERRITORY BEYOND SCHOOL WALLS: THREE KEYS OF ACESS TO MULTIPLE LEARNIG DIMENSIONS}

\section{ABSTRACT}

This study reflects on the daily life of a community on the periphery of the Serra Gaúcha and adopts as its centrality the local municipal school and the surrounding territory, exploring possibilities of learning by promoting a closer relationship between both. The challenge is to focus on the multiple learning dimensions enhanced by access keys categorized through trails in the educational territory (TE), named after three metaphors: the keys to the street; the keys to themselves; the keys to the world. TE as an articulator of relationships contributes to the expansion of school learning, and it can function as a trigger for learning that dialogues with school and community knowledge. Action research, involving 15 young students, was supported by ethnographic records; focus group narratives; definition of educational trails; construction of the 'beyond-the-wall' learning map and photographic records. Theoretical support considered, mainly, the work of Paulo Freire, as well as Brandão and Streck, Moraes and Galiazzi, among others. The detailing of the metaphor of the three keys, configures the main finding of the research: the relevance of the educational territory for learning, in its spatial, identity and political dimensions.

Keywords: Paulo Freire. Educational Territory. Non-School Education. Citizenship. 


\section{PAULO FREIRE Y EL TERRITORIO EDUCATIVO MÁS ALLÁ DE LOS MUROS DE LA ESCUELA: TRES LLAVES DE ACCESO A MÚLTIPLES DIMENSIONES DE APRENDIZAJE}

\section{RESUMEN}

Este estudio reflexiona sobre la vida cotidiana de una comunidad en la periferia de la Serra Gaúcha y adopta como su centralidad la escuela municipal local y el territorio circundante, explorando las posibilidades de aprendizaje al promover una relación más estrecha entre ambos. El desafío es centrarse en las múltiples dimensiones de aprendizaje mejoradas por las claves de acceso clasificadas a través de senderos en el territorio educativo (TE), nombradas por tres metáforas: las claves de la calle; las llaves para ellos mismos; las llaves del mundo. El TE como articulador de relaciones contribuye a la expansión del aprendizaje, y puede funcionar como un disparador para el aprendizaje que dialoga con el conocimiento de la escuela y la comunidad. La investigación de acción, que involucró a 15 jóvenes estudiantes, fue apoyada por registros etnográficos; narrativas de grupos focales; definición de senderos educativos; construcción del mapa de aprendizaje 'más allá de la pared' y registros fotográficos. El soporte teórico consideró producciones de Freire, Brandão y Streck, Moraes y Galiazzi, entre otros. El detalle de la metáfora de las tres claves configura los principales hallazgos de la investigación: la relevancia del territorio educativo para el aprendizaje, en sus dimensiones espacial, identitaria y política.

Palabras clave: Paulo Freire. Territorio Educativo. Educación en la Escuela. Ciudadanía

\section{INTRODUÇÃO}

O cenário investigativo que oportuniza as reflexões deste estudo compreende o cotidiano de uma comunidade de periferia, localizada na região serrana do Rio Grande do Sul. Adota-se como centralidade o sujeito em formação nas dimensões individual e coletiva, na relação entre a escola da comunidade e o território do seu entorno, explorando possibilidades de aprendizagem ao promover uma maior aproximação entre ambos. O desafio consiste 
em tematizar as múltiplas dimensões de aprendizagem potencializadas por chaves de acesso categorizadas por meio das trilhas no território educativo, nomeadas a partir de três metáforas: as chaves da rua; as chaves de si; as chaves do mundo. A pesquisa caracteriza-se, particularmente, por priorizar os espaços externos à escola, indo além dos seus muros, na busca por perspectivas pedagógicas ancoradas na relação com a comunidade.

O conceito de território educativo, do qual partimos ao desenharmos a pesquisa, considera a proposta de Leclerc e Moll (2012, p.44) sobre ser um campo conceitual fundamental para reorganizar a educação escolar e propor novos formatos de aprendizagem. As autoras defendem que "o desafio da promoção de qualidade da educação, traduzida em educação integral, mantém-se associada diretamente à construção da perspectiva de território educativo como elemento organizador da intersetorialidade entre Educação, Assistência Social, Cultura, Esporte e outros campos". O território educativo é compreendido como um articulador das relações entre pessoas e serviços da comunidade, contribuindo para a ampliação do aprendizado escolar e vice-versa. Apoiada nessa concepção, a pesquisa dialoga com temas relacionados à cidadania, aprendizagem, participação juvenil e relação escola-comunidade, explorando o potencial educativo oferecido pelo território, o qual pode funcionar como um disparador de aprendizagens que dialogam com saberes escolares e saberes comunitários.

A sustentação teórica considerou as produções de Brandão e Streck (2006); Moraes e Galiazzi (2011) e, principalmente, Freire (2015, 2015a, 2015b, 2016a, 2016b), dentre outros. O detalhamento da metáfora das três chaves, desenvolvido ao longo do texto, configura os principais achados da pesquisa. Entre os resultados, emergem as categorias construídas a partir da análise textual discursiva de Moraes e Galiazzi (2011): a relevância da integração entre saberes escolares e comunitários; a vivência educativa no território, favorecendo a centralidade nos processos identitários e de pertencimento à comunidade; o fomento à noção de cidadania a partir das experiências no campo; a identificação da necessidade do fortalecimento das relações com e na comunidade e a construção do Mapa das Aprendizagens 'além-muros', bem como do Painel 
Fotográfico como metodologia para o fortalecimento da participação juvenil e incentivo ao poder local.

O artigo está estruturado a partir de quatro elementos centrais: "As trilhas educativas desenhadas pelos pés e com os olhos", em que é descrito o método com base na pesquisa-ação; "A 'chave da rua': potencialidade educativa do além-muros"; "A 'chave de si': centralidade nos processos identitários e de pertencimento à comunidade", e "A 'chave do mundo': fortalecimento da participação juvenil e incentivo ao poder local". Nas seções que têm como referência as chaves de acesso, expressamos os ecos interpretativos da experiência vivida.

\section{AS TRILHAS EDUCATIVAS DESENHADAS PELOS PÉS E COM OS OLHOS - OS PERCURSOS METODOLÓGICOS}

Os percursos metodológicos adotados para a construção dos dados envolveram procedimentos orientados pela pesquisa-ação, desenvolvida com 15 jovens do Ensino Fundamental, matriculados do sétimo ao nono anos na escola da comunidade observada. São eles: registros etnográficos; narrativas produzidas em grupo focal; definição de trilhas educativas da comunidade; construção de mapa das aprendizagens 'além-muros'; registros fotográficos que culminaram em um painel fotográfico.

Uma pesquisa, de acordo com Brandão e Streck (2006, p.13), perfaz-se também em uma pedagogia que conecta "atores-autores", configurando um exercício coletivo de construção do conhecimento. Como aponta Baldissera (2001), a pesquisa-ação não corresponde a um simples levantamento de dados. Ela pressupõe realmente uma ação dos atores implicados no processo investigativo, no caso, a ação de mapear o território do entorno da escola.

No período dos estudos exploratórios, aconteceram rodas de conversa com os estudantes, assim como observação participante em reuniões de professores na escola. Posteriormente, no período da imersão no campo, a partir de abril/2017, foi realizado um grupo focal sobre a temática "relações estudantes - escola - comunidade", com os sujeitos da pesquisa. O passo seguinte envolveu a realização das 
trilhas educativas no entorno da escola, cujos percursos foram definidos coletivamente pelo grupo. As trilhas foram realizadas em dois dias, contando com a participação dos estudantes, acompanhados por uma das pesquisadoras e pela professora da oficina de fotografia4.

A imersão efetiva no cenário da pesquisa, por meio das trilhas educativas, possibilitou realizar um mapeamento do entorno da escola, desafiando os jovens ao registro fotográfico do que identificavam como oportunidades de aprendizagens. Eles registraram, em suas câmeras, equipamentos públicos existentes, como a própria escola, a unidade básica de saúde, a quadra de esportes e a praça da região, além de igrejas, comércios, expressões artísticas nos muros do bairro, horta comunitária e aspectos de vulnerabilidade social. Também houve interação com a vizinhança, cujo contato favoreceu a reflexão sobre a qualidade das relações entre escola e comunidade.

As trilhas duraram aproximadamente duas horas em cada dia, com paradas para debater aspectos observados e para interações com a comunidade que, curiosa, demonstrava apoiar a atividade. Registradas as imagens, houve um trabalho em conjunto com a professora de fotografia, que atua nas atividades extracurriculares da escola. Aproximadamente 500 fotos foram produzidas e visualizadas, das quais 80 foram selecionadas com base nos seguintes critérios: maior diversidade possível de locais fotografados; nitidez e qualidade das fotos; contemplação de imagens registradas pelo conjunto dos participantes.

Após os registros, ocorreram duas rodas de conversa sobre a experiência do mapeamento, nas quais os estudantes puderam expor as suas percepções e ideias que emergiram da vivência. Finalizando a atividade, começamos a pensar em conjunto como seria a forma mais representativa de um mapa da região da escola. Os alunos sugeriram desenhar em cartolina, mas a maioria do grupo concordou que seria mais oportuno o uso de uma imagem aérea da região (obtida por meio do Google Earth). Uma das pesquisadoras providenciou essa

\footnotetext{
${ }^{4}$ Atividade que a escola executa pelo Programa de Ações Educativa Complementares, desenvolvido pela secretaria de educação do município.
} 
imagem com a Secretaria de Planejamento e Gestão do município, impressa em um pôster fotográfico de $85 \times 60 \mathrm{~cm}$.

Com o pôster em mãos, o grupo começou a pensar na melhor maneira de organizar e expor as fotos, planejando dialogicamente a elaboração do painel. Também chegou ao consenso sobre a criação do painel fotográfico, definindo que haveria indicações coloridas no mapa e no painel, sendo que a localidade da foto seria indicada no mapa, além de sinalizar os nomes das ruas percorridas para a consecução da atividade.

O painel com o título que indicava o mapeamento do bairro e o período em que foi realizado (junho de 2017) foi impresso com a dimensão de $120 \times 60 \mathrm{~cm}$ e disponibilizado para os estudantes escolherem as fotos que o comporiam. O grupo foi orientado a criar formas de organização das figuras de modo a serem distribuídas pelo painel a partir da elaboração das categorias representadas no quadro a seguir, com base nos espaços fotografados:

Quadro 1 - Organização do Mapa das Aprendizagens 'além-muros' e Painel Fotográfico em categorias

\begin{tabular}{|l|l|}
\hline \multicolumn{1}{|c|}{ Espaço/Tema } & \multicolumn{1}{c|}{ Motivação } \\
\hline 1 - Topo do painel & $\begin{array}{l}\text { Foram escolhidas imagens que representavam o } \\
\text { grupo percorrendo o bairro, a visão geral do } \\
\text { bairro e o ônibus que transita pelo território }\end{array}$ \\
\hline 2 - Escola "X" & $\begin{array}{l}\text { É o local de origem do grupo e da proposta do } \\
\text { trabalho. }\end{array}$ \\
\hline 3 - Horta Comunitária & $\begin{array}{l}\text { Espaço que auxilia no sustento de moradores da } \\
\text { Vila. }\end{array}$ \\
\hline $\begin{array}{l}\text { 4- Associação } \\
\text { Comunitária }\end{array}$ & $\begin{array}{l}\text { Espaço de reuniões que visa à melhoria das } \\
\text { condições do bairro. }\end{array}$ \\
\hline 5 - "Quadrinha" & Espaço de lazer. \\
\hline 6 - "Igrejinha" & $\begin{array}{l}\text { Ponto de vulnerabilidade que poderia ser melhor } \\
\text { aproveitado (frequentado por pessoas usuárias de } \\
\text { drogas ilícitas). }\end{array}$ \\
\hline $\begin{array}{l}\text { 7 - Praça Colina do } \\
\text { Sol/Academia da 3a. }\end{array}$ & Espaço de lazer bem estruturado da comunidade. \\
\hline
\end{tabular}




\begin{tabular}{|c|c|}
\hline idade e "Parquinho" & \\
\hline $\begin{array}{l}8 \text { - Habitações } \\
\text { estruturadas e } \\
\text { vulneráveis }\end{array}$ & $\begin{array}{l}\text { Mostrar que, na Vila, existem diferentes tipos de } \\
\text { condições sociais. }\end{array}$ \\
\hline $\begin{array}{l}9 \text { - CAPS - Centro de } \\
\text { Assistência e Promoção } \\
\text { Social }\end{array}$ & $\begin{array}{l}\text { Alternativa para que as crianças não fiquem nas } \\
\text { ruas quando não estão na escola. }\end{array}$ \\
\hline $\begin{array}{l}10 \text { - "COMAI" (Centro } \\
\text { Educativo abandonado) }\end{array}$ & $\begin{array}{l}\text { Centro Educativo fechado e abandonado que } \\
\text { poderia ser melhor utilizado. }\end{array}$ \\
\hline $\begin{array}{l}11 \text { - Expressões nos } \\
\text { muros/paredes }\end{array}$ & $\begin{array}{l}\text { Representam algumas formas de pensar da } \\
\text { comunidade. São bonitos. }\end{array}$ \\
\hline $\begin{array}{l}12 \text { - Igrejas e } \\
\text { Comércios }\end{array}$ & $\begin{array}{l}\text { Característica do bairro e valorização do comércio } \\
\text { local. }\end{array}$ \\
\hline 13 - Lixo na rua & Aspecto negativo identificado no bairro. \\
\hline 14 - UBS "Postinho" & Recurso da comunidade para lidar com a saúde. \\
\hline 14 - Decifrando o Vila & $\begin{array}{l}\text { Imagens aleatórias de paisagens consideradas } \\
\text { bonitas ou interessantes. }\end{array}$ \\
\hline
\end{tabular}

Fonte: Elaborado pelos autores (2017).

Optamos por preservar as expressões sobre os recursos da comunidade no diminutivo, como são referidas pelos sujeitos em seus cotidianos. Os estudantes fizeram a colagem das fotos consideradas mais representativas para compor o painel fotográfico. Destacamos que todo o processo de composição, bem como a dimensão estética do trabalho, foi protagonizado pelos jovens. Eles sugeriram, desde o início da elaboração, os materiais a serem providenciados para o mapa e o painel, além de serem os autores das fotografias propriamente ditas. Após a sua conclusão, o painel fotográfico contou com, pelo menos, uma foto de cada estudante, totalizando 42 imagens registradas.

Os três registros fotográficos que seguem, elaborados por uma das pesquisadoras, correspondem ao processo de produção do painel fotográfico, o Mapa das Aprendizagens 'além-muros' finalizado, assim como o painel fotográfico concluído. 
Figura 1 - Produção do Mapa das Aprendizagens 'além-muros'

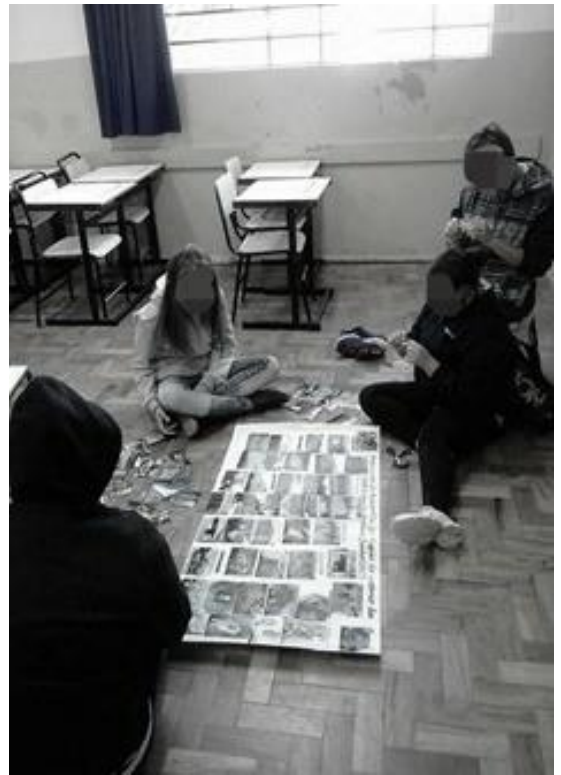

Fonte: Pesquisadores (2017).

Figura 2 - Mapa das Aprendizagens 'além-muros'

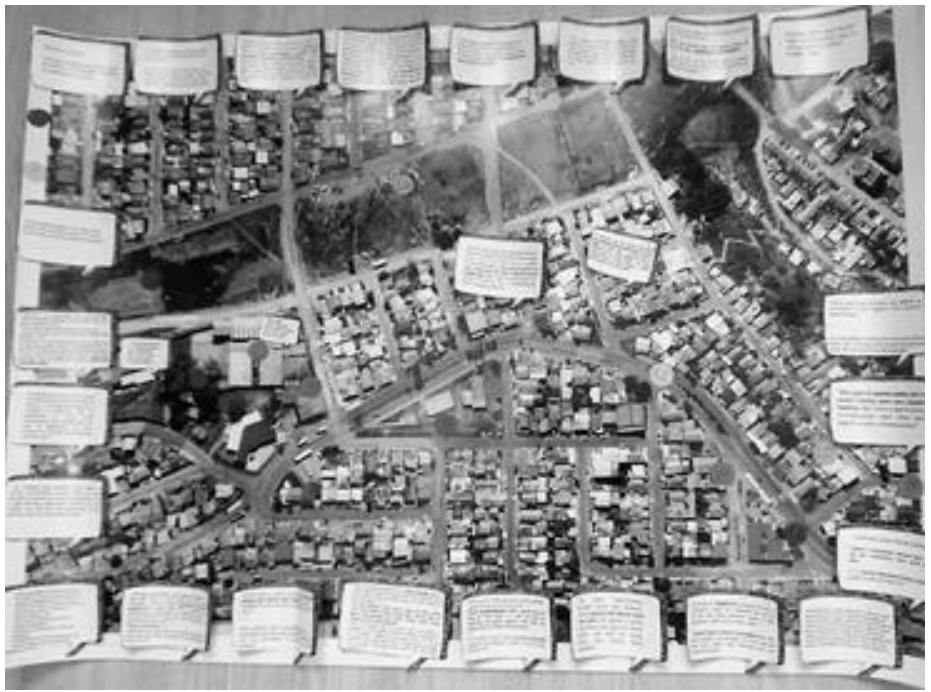

Fonte: Pesquisadores (2017). 
Figura 3- Painel Fotográfico produzido

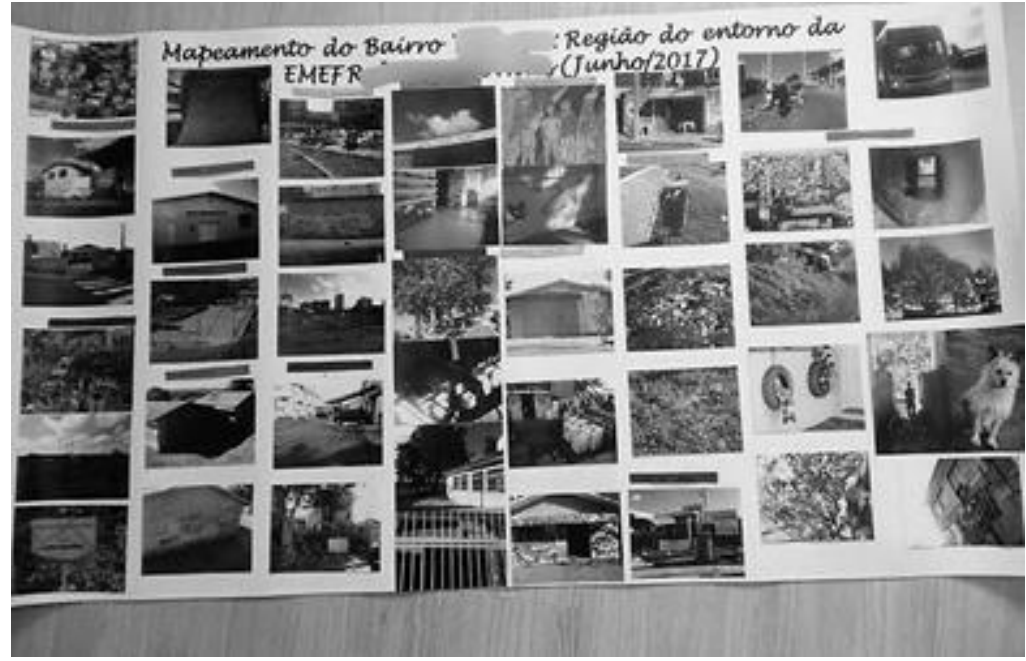

Fonte: Pesquisadores (2017).

A análise que orientou a leitura dos dados construídos, a partir da interpretação das narrativas, do grupo focal e das rodas de conversa, assim como as demais que emergiram durante o processo de pesquisa-ação, deu-se na perspectiva da análise textual discursiva de Moraes e Galiazzi (2011). Por meio das narrativas, foram tematizadas as percepções dos jovens sobre o bairro e a escola, sobre a experiência de mapeamento e sobre as possibilidades de estudos futuros, diante dos achados que foram obtidos. Ademais, desse contexto, emergiram as categorias apontadas na sequência.

O quadro de categorização, cuja síntese será desenvolvida nos próximos tópicos, identifica a metáfora das três chaves de acesso, possibilitadas pelos percursos e vivências no território educativo do campo pesquisado.

Quadro 2 - Síntese da categorização

\begin{tabular}{|c|c|}
\hline $\begin{array}{c}\text { A metáfora das três chaves de } \\
\text { acesso para a decifração do } \\
\text { território educativo }\end{array}$ & Categorização Final \\
\hline $\begin{array}{c}\text { A chave da rua (dimensão do } \\
\text { espaço articulador de relações) }\end{array}$ & $\begin{array}{l}\text { - A relevância da integração entre } \\
\text { saberes escolares e comunitários. }\end{array}$ \\
\hline
\end{tabular}




\begin{tabular}{|c|c|}
\hline & $\begin{array}{l}\text { - O território como articulador de } \\
\text { relações entre pessoas e serviços e sua } \\
\text { contribuição para o aprendizado escolar } \\
\text { e vice-versa. }\end{array}$ \\
\hline $\begin{array}{l}\text { A chave de si (dimensão } \\
\text { identitária) }\end{array}$ & $\begin{array}{l}\text { - A vivência educativa no território } \\
\text { favorece a centralidade nos processos } \\
\text { identitários e de pertencimento à } \\
\text { comunidade. } \\
\text { - O fomento à noção de cidadania a } \\
\text { partir das experiências no campo de } \\
\text { investigação. }\end{array}$ \\
\hline $\begin{array}{l}\text { A chave do mundo (dimensão } \\
\text { política) }\end{array}$ & $\begin{array}{l}\text { - A identificação da necessidade do } \\
\text { fortalecimento das relações com e na } \\
\text { comunidade. } \\
\text { - A construção do Mapa das } \\
\text { aprendizagens 'além-muros' como } \\
\text { metodologia para o fortalecimento da } \\
\text { participação juvenil e incentivo ao Poder } \\
\text { Local. }\end{array}$ \\
\hline
\end{tabular}

Fonte: Elaborado pelos autores (2017).

Como a metáfora das três chaves de acesso considera o território, compreendido como educativo em sua dimensão espacial, identitária e política, podemos dizer que as redes de relações entre os sujeitos perpassam essas três dimensões de aprendizagem. Tais redes assumem dinâmicas específicas a cada uma das chaves de acesso na vivência do cotidiano do território educativo. Dessa forma, a potencialidade transformadora que a experiência educativa pode assumir, tomando como base o bairro, oferece chaves de interpretação para o cotidiano ${ }^{5}$ do território. Também problematiza como o território pode ser vivido de modo a contribuir para a formação dos jovens, partindo da integração dos saberes escolares e comunitários.

\footnotetext{
${ }^{5}$ Pais $(2015$, p.31) apresenta a sociologia do cotidiano em seu aspecto transitivo, passeante "que se vagueia descomprometidamente pelos aspectos anódinos da vida social, percorrendo-os sem, contudo, neles se esgotar, aberta ao que se passa, mesmo ao que se passa no mundo quando nada de passa". Expresso em outros termos, o cotidiano é uma metodologia de questionamento do social que toma, como relevante, aquilo que pode ser aparentemente irrelevante, buscando as rupturas ou surpresas que emergem dos contextos analisados.
} 
Tomando a dialogia como ponto de partida, Freire (2015a) atenta que a prática do educador crítico constitui-se das relações desenvolvidas com os educandos, assim como dos métodos, materiais e técnicas assumidos no processo educativo, demandando coesão e competência. No processo indissociável de leitura das palavras e do mundo, Freire (2015a, p.13) aponta que "a prática educativa de opção progressista jamais deixará de ser uma aventura desveladora". A compreensão dessas múltiplas dimensões de aprendizagem (espacial, identitária e política) favorece a decifração ${ }^{6}$ das potencialidades e vulnerabilidades do território, assim como estimula a vivência de uma cidadania ativa e a noção de pertencimento dos jovens em relação ao bairro onde residem.

Por meio da pesquisa, observamos que o território educativo também traz, em sua constituição, a potencialidade do empoderamento, à medida que amplia a visão dos sujeitos, no caso, os educandos. Como sujeitos políticos, eles podem propor ações, discutir as problemáticas e potências do bairro no espaço escolar e fora dele. A vivência das trilhas tornou essa constatação compreensível pelos sujeitos envolvidos, visto que, no início do processo investigativo, as falas de resignação e de depreciação do território prevaleciam.

Portanto, as trilhas educativas possibilitaram situações de aprendizagem que estimulam o desenvolvimento de seres humanos mais críticos de sua realidade, capazes de intervir nela com potencialidade transformadora.

\section{A "CHAVE DA RUA": a potencialidade educativa do 'além- muros'}

A indagação que enfocou como as oportunidades educativas do território em que a escola está inserida poderiam possibilitar a aprendizagem por meio da integração entre os saberes escolares e os comunitários acompanhou as ações e reflexões do grupo

\footnotetext{
${ }^{6}$ Há uma impossibilidade em desvincular-se o cotidiano do social, sendo que o maior desafio é a decifração da vida social na rotina de todos os dias, tal qual uma "imagem latente de uma película fotográfica" (PAIS, 2015, p.33).
} 
envolvido no processo. Partimos para a identificação dessas oportunidades educativas, estabelecendo espaços de diálogos com diferentes atores - estudantes, funcionários e professores da escola, assim como membros da comunidade.

Observamos, a partir das trilhas realizadas, que tais potencialidades educativas emergem em sentidos diferentes e complementares. Nos equipamentos/serviços que compõem o território cuja dinâmica pode ser explorada no processo de ensino e aprendizagem; na noção de intersetorialidade que integra e articula tais serviços, fazendo valer a noção de rede que representa essa conexão entre os equipamentos do território; na dimensão das parcerias a serem estabelecidas com os responsáveis pelos comércios e indústrias da região; nos espaços públicos de convivência, dentre eles, a própria rua que possibilita observações e reflexões sobre diversas temáticas: expressões artísticas (e de resistência), cidadania, vulnerabilidade social, sustentabilidade, dentre outras; na possibilidade de se vivenciar o território como articulador das relações entre pessoas e equipamentos e sua contribuição na ampliação do aprendizado escolar, e vice-versa e, por fim, na integração entre saberes escolares e comunitários, a partir do currículo escolar integrado com pessoas e espaços da comunidade.

Algumas das narrativas dos estudantes durante as rodas de conversas, que foram realizadas após a vivência das trilhas e da construção do mapa, traduzem as possibilidades de integração dos saberes escolares e comunitários, como os exemplos a seguir: "A horta pode ensinar ciências"; "Em geografia, podemos estudar os tipos de firmas, indústrias, comércios: os tipos de empresas e, em história, a história do bairro"; "Seria interessante chamar o Presidente do bairro para a gente dizer o que acha do bairro e entender o que ele faz". "Seria legal, a gente fazer o que fez aquele dia, entrevistar as outras pessoas, para a gente saber mais as opiniões das outras pessoas, para ajudar nas melhorias do bairro".

A prática educativa desenvolvida a partir do mapeamento não deixa de figurar, também, como uma prática cultural constituída por movimentos e ações inventivas. Neste sentido, ela é capaz de ressignificar o bairro para os estudantes e fomentar diálogos, 
transformando os percursos pelo espaço, na perspectiva apontada por Certeau (1994), em territórios de aprendizagem.

Identificadas as oportunidades educativas e tendo alguns exemplos sobre como elas podem possibilitar aprendizagens no 'além-muros', torna-se importante compreender a concepção do território educativo (TE) como uma possibilidade de enfrentamento à educação bancária, problematizada por Freire (2016a; 2016b). A prática pedagógica integradora no TE pode configurar-se como uma forma de reinventar a recomendação de que é preciso partir da realidade dos educandos. Com isso, atribuímos sentido às relações com o currículo escolar, aproximando-o do cotidiano dos sujeitos e de sua compreensão do mundo, que deve ser aprofundada. Favorecendo o contato com a realidade próxima, de forma dinâmica, - TE revela-se como um cenário a ser problematizado dialogicamente, na contramão da educação dissertadora. Neste aspecto, entendemos essa educação, de acordo com Freire (2016a, p.80), como a "mera sonoridade das palavras", que não condiz a sua potencialidade transformadora.

Ao experienciar uma prática pedagógica que considera a realidade próxima do educando, como o seu bairro e a sua vizinhança, as condições tornam-se favoráveis para tomar-se, como ponto de partida, o "saber de experiência feito", ou seja, as experiências de aprendizado que os educandos constituem ao longo de suas vidas e as suas percepções. "Sem que o educador se exponha inteiro à cultura popular, dificilmente seu discurso terá mais ouvintes do que ele mesmo" (FREIRE, 2015a, p.148).

Em um modelo de aula exclusivamente narrador e estritamente "ensinante", esse saber de experiência feito dificilmente será resgatado, limitando-se ao que Freire (2016a) chama de experiência transmitida. De maneira oposta, contatando pessoas e instituições, caminhando pelo bairro e fotografando, mediados pela dialogicidade do educador, os estudantes encontram condições consistentes para colocar em uso seus conhecimentos prévios em um processo de aprendizagem problematizador e crítico.

O educador ou educadora, propondo um uso estético e ético do espaço (Freire, 2016b) e sustentado em princípios de educação progressista e libertadora, cria condições para que os educandos 
possam questionar a lógica da acomodação passiva. Ao mesmo tempo, esse sujeito atuante na educação estimula o processo de transformação do mundo a partir da transformação de si:

Por que não aproveitar a experiência que tem os alunos de viver em áreas da cidade descuidadas pelo poder público para discutir, por exemplo, a poluição dos riachos e dos córregos e dos baixos níveis de bem-estar das populações, os lixões e os riscos que oferecem à saúde das gentes. Por que não há lixões no coração dos bairros ricos e mesmo puramente remediados do centro urbano? Essa pergunta é considerada em si demagógica e reveladora da má vontade de quem a faz. É pergunta de subversivo, dizem certos defensores da democracia (FREIRE, 2016b, p. 32).

Tomar o contexto local como ponto de partida, de acordo com Freire, configura-se como estratégia significativa, que, além de representar respeito ao saber popular e ao contexto cultural, oportuniza ao educando que parta da sua experiência de vida e convivência. Afinal, esse seu mundo corresponde "a primeira e inevitável face do mundo mesmo" (FREIRE, 2015a, p.119).

Nessa configuração, é importante que o educador conduza a sua prática educativa em comunhão com os educandos, explicitando as relações de influência que ocorrem entre o vivenciado no local (bairro), com a cidade como um todo, assim como com as diferentes culturas que formam o país, em uma articulação sistêmica. "Assim como é errado ficar aderido ao local, perdendo-se a visão do todo, errado é também pairar sobre o todo sem referência ao local de onde se veio" (FREIRE, 2015a, p.121).

Freire (2016a) também aponta a importância de que, na investigação educativa, a consideração da integralidade do ser humano esteja manifesta em sua visão de mundo, nos níveis de percepção da realidade e na maneira como pensamento e linguagem articulam-se em relação a essa realidade. Tal referência foi vivenciada nas trilhas educativas e rodas de conversa, sendo observado que os estudantes, após a atividade do mapeamento, trouxeram mais 
percepções, para além das depreciativas, em relação ao seu próprio bairro.

A partir dos relatos dos educandos sobre a relação território/escola, que foi expressa e ilustrada pelo mapeamento, foi possível perceber anseios, dúvidas, sugestões, esperanças e desesperanças, o que, de acordo com Freire (2016a), pode servir como base na constituição do conteúdo programático da educação naquela escola. Essa vivência foi compartilhada em reunião com os professores, de modo que uma das estudantes envolvidas no mapeamento dispôs-se a protagonizar a apresentação juntamente com uma das pesquisadoras. Os demais estudantes, apesar de simpáticos à proposta, no dia da apresentação, não compareceram.

A possibilidade de protagonizarem a apresentação foi deixada em aberto à medida que compreendemos que a falta de vivências nesse sentido intimida os estudantes. Além disso, normalmente, eles acabam associando a experiência a uma atividade avaliativa. A importância do incentivo ao pensamento crítico e à apropriação dos canais participativos da escola (grêmio estudantil e conselhos) figuraram como uma temática significativa, repassada à coordenação pedagógica e aos professores, tanto na devolutiva do trabalho como na reunião pedagógica.

Alguns professores manifestaram intenção de propor experiências educativas que integrassem os saberes comunitários aos escolares. Outros demonstraram ainda não estarem preparados, como revela a afirmação de uma professora: "Tenho medo de andar pelo bairro". A maioria permaneceu receptiva, embora em uma postura bem mais espectadora do que problematizadora. A apresentação de parte dos resultados da pesquisa nessa reunião teve o propósito de compartilhar a experiência como uma possibilidade de disparar ações relacionadas à concepção da prática educativa no território. O que buscamos refletir junto aos professores e equipe diretiva foi a ideia inspirada por Freire (2016a) sobre a função mediatizadora do território, na relação dos sujeitos com a educação, além de estimular a ação transformadora deles em seu processo de humanização, do qual a escola faz parte.

Weffort (2014, p. 19, apud Freire, 2014) identifica aspectos convergentes entre a obra de Paulo Freire e a pedagogia moderna: 
"uma educação para a decisão, para a responsabilidade social e política". Neste sentido, a vivência da criticidade e da dialogicidade na perspectiva do TE favorece indícios dessa concepção de educação. A escola não pode estar desvinculada da condição do estudante, "não é possível à escola, se, na verdade, engajada na formação de educandos e educadores, alhear-se das condições culturais, sociais e econômicas de seus alunos, de suas famílias, de seus vizinhos" (FREIRE, 2016b, p.62).

A aproximação do professor com a realidade dos estudantes, muitas vezes, começa quando ele dispõe-se a transitar pelo mesmo espaço concreto dos outros. "Como ensinar, como formar sem estar aberto ao contorno geográfico, social, dos educandos?" (FREIRE, 2016b, p.134). A travessia pelo TE ajuda a diminuir as distâncias entre educador e educando, perfazendo uma aproximação gradual e o estabelecimento de relações afetivas. Tende, desse modo, a qualificar o processo de ensino e de aprendizagem, figurando como aliada ao domínio técnico presente na atuação dos professores.

Os saberes comunitários acessados nos dois dias de mapeamento, nas conversas estabelecidas com os moradores do bairro, ou ainda no contato com a profissional da assistência social visitada demonstraram o quanto incentivar a comunicação entre estudantes e comunidade, na perspectiva da educação emancipatória, pode ser benéfico ao processo crítico reflexivo dos sujeitos.

\section{A "CHAVE DE SI": a centralidade nos processos identitários e de pertencimento à comunidade}

A experiência de trânsito pelo território compreendido como educativo também propiciou reflexões sobre o quanto essa prática está vinculada aos processos identitários e de pertencimento à comunidade. Compreendemos, como identitários, os processos constituidores do desenvolvimento da identidade. De acordo com Naujorks (2011), há quatro elementos comuns nos diferentes entendimentos e perspectivas acerca do conceito: a produção da identidade como decorrência das relações sociais, a presença de 
processos cognitivos e afetivos em sua constituição, a identidade envolvendo tanto a esfera individual como a coletiva e, por fim, relacionada a processos de diferenciação social e reconhecimento.

O processo identitário pode ser considerado "como um conjunto de processos cognitivos e afetivos, de construção e atribuição de significados que pessoas, individual e coletivamente, elaboram sobre si mesmas, outras pessoas e grupos e a sociedade a partir de referências pessoais e socialmente construídas" (NAUJORKS, 2011, p.30). À medida que o processo identitário, socialmente construído, é também influenciado historicamente, recorremos a Freire (2016a, 2016b) na compreensão da historicidade que permeia a relação dialética ser humano-mundo. Fiori (2016, apud FREIRE, 2016a, p.13) afirma que, no pensamento freireano, "a pedagogia fazse antropologia", disparando o processo de historicizar-se do ser humano. Tornado sujeito, o ser humano se reconhece como protagonista de sua experiência existencial, assim como se vê em relação dialética com o mundo, podendo transformá-lo e ser transformado por ele, além de libertar-se a partir da tomada de consciência crítica.

Essa tomada de consciência, que pode ser possibilitada pela educação dialógica, permite que o ser humano não somente se adapte ao mundo, mas se insira nele e, conforme Freire (2016a, 2016b; FREIRE, P.; FREIRE, A., 2013), lute para confirmar-se como sujeito da história. Assim sendo, ele reconhece o seu inacabamento e compreende o mundo para além de um suporte, ${ }^{7}$ como um contexto, um lugar histórico de transformação e a vida como existência.

De acordo com Sposati (2013, p.8), contextualizar, espacialmente, a história, conforme a pesquisa propôs-se em relação ao TE "permite o conhecimento de estradas, caminhos, marchas e contramarchas, movimentos, contornos particulares, heterogeneidades, diversidades e desigualdades". A historicidade em um chão de relações favorece a leitura de expressões da questão social. A experiência no território, em sua dimensão educativa, como

\footnotetext{
7 Para Freire (2016a), o animal, como a-histórico, relaciona-se com o mundo, como um suporte, à medida que não pode transformá-lo. Já o mundo com o qual o ser humano coloca-se em relação dialética é simbolicamente construído, a partir da cultura e da história.
} 
um lugar histórico, passível de transformações e simbolizações, é constituidora de processos identitários que se estabelecem a partir das significações pessoais e das relações coletivas:

Trabalhar a categoria território significa, ao mesmo tempo, reconhecer sua particularidade e suas possibilidades de conexão. Outra analogia pode, aqui, ser realizada: a identidade de cada um é resultante de um processo relacional, pois a identificação da individualidade decorre da conexão com os outros. Assim, é pela realização de conexões que ocorre o reconhecimento da particularidade da identidade (SPOSATI, 2013, p.8).

Reconhecer-se como ser histórico é também reconhecer-se como sujeito em movimento ("estar sendo"), como possibilidade em contraposição ao determinismo. A noção de pertencimento à comunidade também pode ser despertada ou acentuada a partir da experiência do território educativo, contribuindo no movimento de se assumir como sujeito e estabelecer relações de alteridade.

Estabelecer percursos de aprendizagem na perspectiva do bairro como território educativo provoca movimentos de resistência à visão estigmatizada presente (e verbalizada) em outras regiões da cidade. Tais visões compreendem a periferia como lugar de negatividades (visão reproduzida nas narrativas dos próprios estudantes). Neste sentido, a dimensão da criatividade por parte dos educadores e educandos favorece o enfrentamento ao pensamento hegemônico, que deprecia e desvaloriza as regiões mais pobres da cidade.

A ação de fotografar aspectos do território como representações da realidade, para além da comunicação verbal, possibilitou aos jovens revelarem parte dos conhecimentos que possuem sobre o mundo, podendo também configurar-se como um processo identitário. Conforme Pais (2006, p.58),

toda fotografia é um certificado de presença: não uma simples representação - sucedâneo de um referente real ou imaginário - um atestado de existência na medida em que ratifica a presença deste mesmo referente. 
O registro fotográfico, que atesta existência do território percorrido, legitima, na mesma medida, a autoria e o protagonismo dos jovens que transitam por ele diariamente. Ademais, complementa e amplia o reconhecimento dos aspectos verbalizados como enfrentamentos diários: a violência, o preconceito e as carências da comunidade, mas também revela e potencializa (estimuladas pelo diálogo) reflexões acerca de possíveis caminhos e soluções para resolver ou lidar com suas problemáticas.

A potencialidade formadora da experiência educativa de base humanista pressupõe dialogicidade, portanto, comunicação. Freire (2016a) aponta o diálogo como caminho da libertação: o diálogo que permite o exercício da criticidade e da problematização, levando ao reconhecimento das realidades vivenciadas e possíveis releituras das situações significadas, como da violência. Nesse cenário, a relevância do educador é significativa, sendo que a consideração da identidade cultural dos educandos, assim como a dimensão individual e a classe social a qual eles estão vinculados são elementos fundamentais para o desenvolvimento de uma prática educativa progressista (FREIRE, 2016b).

Considerar a dimensão do TE e problematizá-lo junto aos educandos é também considerar a experiência histórica, política, social e cultural dos jovens que transitam nele, que pensam sobre ele e que pouco falam a respeito, conforme mencionado nas rodas de conversa. Propiciar um espaço de diálogo sobre o TE não deixa de figurar como uma forma de exercício do pensamento crítico, que pode fomentar noções de cidadania e pertencimento.

Estar próximo espacialmente não necessariamente significa ter um sentimento de comunidade, ou mesmo de pertencimento ao lugar, de acordo com Marques (2010). No entanto, também é inegável que viver em situações adversas, demarcadas pela vulnerabilidade social, requer redes relacionais que podem ser fortalecidas a partir de experiências como a relatada. Essa experiência considerou a dimensão histórica do bairro e despertou nos estudantes, conforme narraram, a curiosidade de dialogar com os demais moradores em busca de soluções para o território.

A construção da cidadania relaciona-se com a democratização e o fortalecimento do poder local (temática que desenvolveremos no 
próximo item). Um poder que se relaciona com a possibilidade de transitar e vivenciar o território a partir de um processo educativo que possibilite pensá-lo e promover estratégias de organização coletiva para transformá-lo.

Essa dimensão tornou-se evidente quando os estudantes demonstraram interesse em estreitar relações com os moradores do bairro, entrevistando-os sobre as problemáticas vivenciadas no dia a dia. Neste sentido, eles sugeriram, inclusive, uma entrevista com o Presidente da Associação de Moradores para entender melhor essa função, além de verbalizarem que, antes, não compreendiam a escola como um local de reflexão e ação em relação à realidade do bairro.

A cidade é considerada como educadora e como educanda, já que afeta e é afetada pelas relações que se estabelecem nela. Gadotti (2006) frisa que, para alcançar essa configuração, além de cumprir as funções econômicas, sociais, políticas e de prestação de serviços, a cidade também passa a exercer um papel de formação para e pela cidadania, fazendo valer a noção de protagonismo. Cabe, efetivamente, ocupar a cidade. Ocupar o bairro e ocupar a cidade, assim como percorrê-los e pensar sobre eles, sobre a melhoria da qualidade de convívio nesses espaços praticados, revelando uma perspectiva de desenvolvimento da autonomia e do protagonismo entre os jovens. Assim, essas noções auxiliam-nos a acessar a "chave de si" nesse percurso de integração à vivência da cidadania.

\section{A "CHAVE DO MUNDO": fortalecimento da participação juvenil e incentivo ao poder local}

No processo de análises e interpretação do que ouvimos e observamos durante a experiência do trabalho de campo junto aos jovens, sobretudo, quanto a não terem o hábito de problematizar questões referentes ao bairro em que vivem, começamos a compreender a construção do mapa. Incluímos as rodas de conversas, estratégias, trilhas e registros fotográficos como uma metodologia para fortalecimento da participação social e, consequentemente, um incentivo ao desenvolvimento do poder local. 
Os jovens, na roda de conversa realizada após o mapeamento, apontaram que faltam lideranças na região e que não têm conhecimento de quem são os atores sociais que mobilizam o território. Há narrativas que evidenciam a união da comunidade, partindo de exemplos de redes de solidariedade, no caso de doação de alimentos ou de casas afetadas por temporais. Mas também aparecem relatos de que a participação e a articulação da comunidade precisam ser estimuladas.

No Brasil, o histórico de atuação dos movimentos sociais que caracterizam a participação social e o poder local remete aos processos de industrialização e expansão urbana. As periferias configuraram-se como áreas mais distantes do acesso aos direitos fundamentais, o que demandou articulação e emersão de movimentos reivindicatórios mais consolidados nessas regiões das cidades, em comparação às regiões mais elitizadas. Esses movimentos adquiriram grande expressividade no período da ditadura militar (1964-1985):

A complexificação do tecido social brasileiro, com a
emergência de inúmeras organizações e
movimentos populares de base, permite a
introdução de novos temas na agenda pública,
vocaliza as demandas sociais emergentes e
constitui-se em recurso organizacional que produz
o adensamento da sociedade civil e o aumento do
capital social (FLEURY, 2003, p.250).

Articulando a possibilidade de fortalecimento da participação social dos jovens ao desenvolvimento do poder local, nomeamos a terceira chave de acesso às decifrações dos enigmas do TE como "a chave do mundo". Consideramos, neste aspecto, que o empoderamento político favorece e organiza o agir coletivo, potencializador da transformação do mundo.

Pensar na questão da participação social envolve desde o processo escolar até outros segmentos da sociedade. A participação dos educandos no conteúdo programático, assim como da comunidade, em uma proposta de gestão democrática na escola é uma questão, de acordo com Freire (2015a), de caráter político e ideológico. Logo, o papel das famílias, das organizações sociais e da 
comunidade local no cenário escolar é problematizado pelo educador. Nesse contexto, torna-se importante resgatar uma dimensão histórica dos conceitos de participação social e poder local que a prática pedagógica no TE pode provocar.

Na dimensão da participação social, Freire (2014) aponta para o fato que, na formação histórico-cultural do Brasil, destaca-se a nossa inexperiência democrática. Raramente, foi estimulado um comportamento participante que nos constituísse como povo, tendo em vista o processo de colonização que, em sua estrutura, foi "uma empreitada comercial", na qual não houve a intenção de se criar uma civilização (FREIRE, 2014, p.91).

O autoritarismo da educação brasileira, pautado na transmissão de conteúdos em que não há espaço para diálogos e argumentos, do qual Freire e Guimarães (2011, p.45) são críticos, expressa, segundo os autores, desdobramentos do centralismo na política brasileira: "o centro sabe e fala, a periferia do país escuta e segue". Educação e política, portanto, não podem ser dissociadas, havendo reflexos de uma na outra. Freire $(2014$, p.93) ainda demarca que o processo colonizador ao qual o Brasil foi submetido pautou-se, territorialmente, nos latifúndios - da fazenda e do engenho apropriados por uma pessoa só, na figura de um "senhor", símbolo do poder e da proteção aos demais habitantes da região. "Aí se encontram, realmente, as primeiras condições culturológicas em que nasceu e se desenvolveu no homem brasileiro o gosto, a um tempo de mandonismo e de dependência, de 'protecionismo', que sempre floresce em nós em plena fase de transição".

Tal caráter paternalista acaba por gerar o que Freire (2014) chama de "mutismo", como falta de teor crítico, de modo que a ausência de diálogo compromete negativamente a responsabilidade social e política do ser humano. Dessa estrutura patriarcal, escravocrata e latifundiária, o que herdamos foi a "não-participação" na solução dos problemas comuns.

Ainda que de forma fragmentada, começam a emergir características do poder local, visando à transformação, o que é traduzido nos movimentos sociais de reivindicação dos direitos fundamentais, convivendo, neste caso, em conflito com a "tradição" representada por "estruturas institucionais tradicionais, enfeudadas 
por grupos das elites políticas e econômicas, práticas sociais patrimonialistas, clientelistas, corruptas e excludentes e com novas orientações políticas que privilegiam as soluções via mercado e retiram do Estado atribuições e funções" (FLEURY, 2003, p.244).

Vieira (2011) relaciona "poder local" às instâncias mais próximas dos cidadãos como o município, o distrito e o bairro. Neste sentido, O TE pode ser considerado como palco para o desenvolvimento do poder local, que, muitas vezes, precisa constituir-se como enfrentamento à noção de poder central, não deixando, porém, de serem instâncias complementares. O poder local organizado, perpassado por um processo educativo e dialógico, pode assumir caráter reivindicatório, considerando a realidade da comunidade, buscando canais de acesso à esfera do poder central:

A esfera local é o espaço por excelência onde cidadãos e cidadãs exercem protagonismo como seres de direitos e de deveres. É, pois, nesse âmbito que o governo da educação ganha sentido e se fortalece. Não por acaso as questões do território têm adquirido maior visibilidade na reflexão sobre a gestão educacional e escolar. O território é espaço por excelência da vida cotidiana. Nele, portanto, a força da escola, da comunidade e de outras agências do poder local fazem diferença (VIEIRA, 2011, p.131).

Compreender a construção do mapa como uma metodologia para fortalecimento da participação dos jovens e incentivo ao poder local pressupõe um trabalho educativo no território pautado pela concepção de dialogicidade freireana. A democratização da escola, nesse processo das aprendizagens no $T E$, torna-se fundamental, assumindo, de acordo com Freire (2015a), papel indutor da democratização da sociedade.

O poder local, seja ele constituído por jovens incentivados pela gestão democrática da escola ou por demais membros da comunidade, precisa estar organizado e, em conformidade com Freire (2016a), desvinculado do pensamento "mágico e mítico" que vincula sujeitos oprimidos ao mundo da opressão. Neste sentido, a ação dialógica visa proporcionar que os oprimidos compreendam e 
reconheçam o processo de opressão ao qual estão submetidos, assumindo "um ato de adesão à práxis verdadeira de transformação da realidade injusta" (FREIRE, 2016a, p.237).

Dessa forma, territórios educativos conduzidos e problematizados pela trilha da ação dialógica podem converter-se dialeticamente em territórios de participação social, à medida que a politicidade é uma concepção que perpassa os atos de educar e de participar socialmente. Com os acessos decifrados pela 'chave do mundo', historicizados pelo caminho do diálogo e passíveis de transformação na relação dialética com o ser humano, territórios educativos podem configurar-se em territórios de resistênciaesperança.

Resistência-esperança é um par que se retroalimenta dialeticamente. Havendo a atitude do enfrentamento, sustentada pela prática educativa-reflexiva e tracejada pela trilha da consciência crítica, haverá também condições para que a esperança resista e acompanhe nossos próximos passos.

\section{CONSIDERAÇÕES FINAIS}

Para a elucidação da pergunta sobre como as oportunidades educativas no além muros da escola poderiam possibilitar a aprendizagem por meio da integração entre os saberes escolares e os comunitários, a resposta constituiu-se a partir das vozes dos diferentes estudantes. Após o exercício das trilhas, eles e elas trouxeram sugestões de aulas que poderiam ser desenvolvidas para além dos muros da escola. Como exemplos, aula de ciências na horta comunitária ou a aula de geografia a partir da investigação dos diferentes tipos de empresas do bairro, além da sugestão de se estudar a história da comunidade observada na pesquisa.

Os estudantes demonstraram pouco conhecimento sobre as instâncias participativas existentes no bairro, como a Associação de Moradores e o Conselho Local de Saúde que se reúne na Unidade Básica de Saúde, assim como as que existem na própria escola, como o Grêmio Estudantil e os Conselhos de Classe, apesar de conhecê-las, de modo que este é um saber comunitário a ser explorado (isso foi 
sugerido para a escola na devolutiva dos dados, na apresentação dos resultados compartilhados com os professores).

No exercício sensível da escuta das vozes do campo, assim como na observação desenvolvida ao longo desse percurso, compreendemos que um estudo sobre o território em sua dimensão educativa integra diferentes aspectos e temáticas para debates e diálogos: a perspectiva das relações constituidoras do "eu-nós" mediatizadas pelo território, inspirada na concepção freireana, assim como a compreensão do TE como uma possibilidade de enfrentamento à educação bancária, desde que a prática seja desenvolvida pela via do diálogo e estimule a consciência crítica.

Viver e percorrer o território na perspectiva da Educação Problematizadora, conjugando teoria e prática, contribuiu para que os estudantes ampliassem suas percepções sobre os espaços por onde caminham cotidianamente. Foram observadas variações nas narrativas dos colaboradores, que, inicialmente, caracterizavam-se como depreciativas do bairro, mas que, ao longo dos diálogos e vivências, trouxeram também percepções positivas da comunidade. Ademais acrescentaram teor crítico às percepções negativas que possuíam, além de sugestões de mobilização para mudança de tais condições. Neste aspecto, sinalizamos uma das potências do trabalho realizado com base na pesquisa-ação.

A metáfora das três chaves de acesso para a decifração do território educativo oferece uma perspectiva de leitura que abrange as múltiplas dimensões de aprendizagem possibilitadas a partir das trilhas vivenciadas e representadas. Essas aprendizagens envolvem o espaço do bairro como um articulador de relações entre a comunidade, integrando desde o aspecto físico e sensorial dos educandos (que engloba o caminhar e o perceber) ao exercício do pensamento crítico, constituidor do sujeito, da dialogicidade, da ação mobilizadora e dos saberes construídos na coletividade. Neste sentido, 'rua', 'si mesmo' e 'mundo' são chaves interpretativas para o caráter educativo que permeia as relações que se dão em uma dada espacialidade, a constituição identitária e o exercício político.

O presente estudo reafirma, na dimensão freireana do inacabamento, a reflexão sobre um deslocamento fundamental a ser provocado: da centralidade da instituição-escola nos processos de 
aprendizagem para a centralidade no sujeito, a partir de valores como reconhecimento, acolhimento, valorização da diversidade e do diálogo com a cidade (considerando o território como educativo, palco de participação social).

Integram-se a tal processo, numa perspectiva potencializadora, o compromisso com a humanização e com a transformação social, imperativos existenciais preconizados por Freire, para a prática de uma educação libertadora, conectada com o coletivo e que favoreça a construção de uma cidadania crítica, participativa.

\section{REFERÊNCIAS}

BALDISSERA, A. Pesquisa-ação: uma metodologia do "conhecer" e do "agir" coletivo. Sociedade em Debate, Pelotas, v. 7, n. 2, p. 5-25, ago. 2001.

BRANDÃO, C. R.; STRECK, D. R. Pesquisa participante: o saber da partilha. Aparecida: Ideias \& Letras, 2006.

CERTEAU, M. de. A invenção do cotidiano: 1 Artes de Fazer. Petrópolis: Vozes, 1994.

FLEURY, S. Democracia, poder local y ciudadania em Brasil. In: GOMÁ, R.; JACINT, J. Descentralización y políticas sociales en América Latina. Barcelona: Fundación CIDOB, 2003.

FREIRE, P. Ação cultural para a liberdade e outros escritos. 15 ed. Rio de Janeiro: Paz e Terra, 2015b.

FREIRE, P. Educação como prática da liberdade. 38. ed. São Paulo: Paz e Terra, 2014.

FREIRE, P. Pedagogia da autonomia: saberes necessários à prática educativa. 53. ed. Rio de Janeiro: Paz e Terra, 2016b.

FREIRE, P. Pedagogia da esperança: um reencontro com a pedagogia do oprimido. 22. ed. São Paulo: Paz e Terra, 2015a.

FREIRE, P. Pedagogia do oprimido. 62. ed. Rio de Janeiro: Paz e Terra, 2016a. 
FREIRE, P.; FREIRE, A. M. de A. À sombra desta mangueira. 11. ed. Rio de Janeiro: Paz e Terra, 2013.

FREIRE, P; GUIMARÃES, S. Partir da Infância: Diálogos sobre Educação. 1. ed. São Paulo: Paz e Terra, 2011.

GADOTTI, M. A escola na cidade que educa. Cadernos Cenpec, São Paulo, n.1, p. 133-139, 2006.

LECLERC, G.; MOLL, J. Educação integral em jornada diária ampliada: universalidade e obrigatoriedade? Em Aberto, Brasília, v.25, n. 88, p. 17-49, jul./dez 2012.

MARQUES, E. C. Redes sociais, segregação e pobreza. São Paulo: Unesp/Centro de Estudos da Metrópole, 2010.

MORAES, R.; GALIAZZI, M. do C. Análise Textual Discursiva. Ijuí: Editora Unijuí, 2011.

NAUJORKS, C. J. Processo identitário e engajamento: um estudo a partir do Movimento de Saúde do Trabalhador no Rio Grande do Sul. 2011. 294 f. Tese (Doutorado em Sociologia) - Universidade Federal do Rio Grande do Sul, Programa de Pós-Graduação em Sociologia, Porto Alegre, 2011.

PAIS, J. M. Lufa-lufa quotidiana: ensaios sobre cidade, cultura e vida urbana. 2. ed. Lisboa: Imprensa de Ciências Sociais, 2015.

PAIS, J. M. Nos rastos da solidão: deambulações sociológicas. 6. ed. Porto: Ambar, 2006.

SPOSATI, A. Território e gestão de políticas sociais. Serviço Social em Revista, Londrina, v. 16, n.1, p. 05-18, jul./dez. 2013.

VIEIRA, S. L. Poder local e educação no Brasil: dimensões e tensões. Revista Brasileira de Política e Administração da Educação, Porto Alegre, v.27, n.1, p. 123-133, jan./abr. 2011.

Submetido em: Julho/ 2021.

Aceito em: Agosto/ 2021. 